U.S. GEOLOGICAL SURVEY CIRCULAR 977

Principles of Logic and the Use of Digital Geographic Information Systems 
I had always believed logic was a universal weapon, and now I realized how its validity depended on the way it was employed. (Umberto Eco, The Name of the Rose, p. 312) 
Principles of Logic and the Use of Digital Geographic Information Systems

By Charles J. Robinove

U.S. GEOLOGICAL SURVEY CIRCULAR 977 


\section{DEPARTMENT OF THE INTERIOR DONALD PAUL HODEL, Secretary \\ U.S. GEOLOGICAL SURVEY \\ Dallas L. Peck, Director}

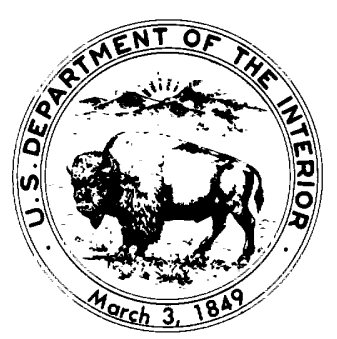

Library of Congress Cataloging-in-Publication Data

Robinove, Charles Joseph, 1931-

Principles of logic and the use of digital geographic information systems.

(U.S. Geological Survey circular ; 977)

Bibliography: p. 19

Supt. of Docs. no.: I 19.4/2:977

1. Geography -Data processing. I. Title. II. Series.

G70.2.R63 $1986 \quad 025^{\prime} .0691 \quad 86-600043$

Free on application to the Books and Open-File Reports Section, U.S. Geological Survey, Federal Center, Box 25425, Denver, CO 80225 


\section{CONTENTS}

Abstract

Introduction

Designing a geographic data base

Logical axioms for data used by geographic information systems

What is a class?

The relations among classes

The problem of holism and reductionism

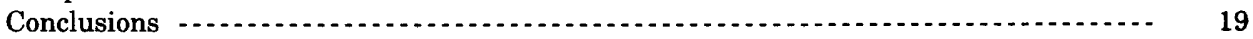

Selected references

\section{ILLUSTRATIONS}

FIGURE 1. Schematic diagram of two classes in map form

2. Venn diagrams of the logical products of two classes

3. Schematic diagram of the null class

4. Schematic diagram showing logical relations of spatially located classes _... $\quad 7$

5. Venn diagram showing relations among water-well pumpage, decline of
water level, and salt concentration of water

6. Maps showing gradient proximity mapping and masking

7. Spatial representations of the influence of point data

8. Spatial representations of the influence of data represented by a line $\ldots . . . . . \quad 12$

9. Venn diagram of mapped sets and intersections of sets for water bodies and disposal sites in a river basin

10. Maps showing sets and intersections of sets of water and waste-disposal

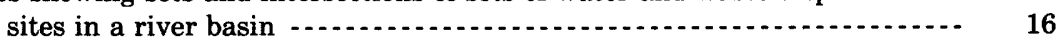

11. Map showing combinations of individual sets and intersections of sets 



\title{
Principles of Logic and the Use of Digital Geographic Information Systems
}

\author{
By Charles J. Robinove
}

\begin{abstract}
Digital geographic information systems allow many different types of data to be spatially and statistically analyzed. Logical operations can be performed on individual or multiple data planes by algorithms that can be implemented in computer systems. Users and creators of the systems should fully understand these operations. This paper describes the relationships of layers and features in geographic data bases and the principles of logic that can be applied by geographic information systems and suggests that a thorough knowledge of the data that are entered into a geographic data base and of the logical operations will produce results that are most satisfactory to the user. Methods of spatial analysis are reduced to their primitive logical operations and explained to further such understanding.
\end{abstract}

\section{INTRODUCTION}

The purpose of this report is to explore, in a philosophical sense, the creation and use of digital geographic information and systems from the standpoints of the creator and the user. It is vital to the proper operation of geographic information systems that basic principles of logic be followed, that the limits of what a system can or cannot be expected to do be well understood, and that the relations, both logical and spatial, among the various data elements be understood.

To avoid confusion, two terms need to be defined. These terms have been used in a somewhat loose manner in the literature. For a precise understanding of this report (although some may disagree with the specific definitions), the terms are defined below.

Geographic data base. A collection of digital map data in which each feature is referenced to a geographic location expressed in spatial coordinates. Data may be points, lines, or areas. The data base is analogous to a single map or a set of map overlays. It may also be referret to as a "spatial data base."

Geographic information system (GIS)、 A collection of computer programs in a giv?n hardware environment which operate on a geographic data base to analyze individual data-base elements or for synthesis of multiple data-base elements. A GIS takes into account the spatial position of each element as well as its other characteristics.

This definition includes image-processing programs and computer-aided mapping programs as well as software packages that are specifically designated by their devel ppers as "geographic information systems." A digital geographic data base can be visualized by an analogy with a series of map overlays. McHarg (1969) has successfully used a map-overlay system to display the common attributes of selected areas in order to make decisiors on the type and degree of land development that is commensurate with the physical properties and limits of an area. A digital geographic information system may use the same data as a mapoverlay system, but because the data are in digital form, the system is much more flexible in the type and amount of the data it car handle, in the logical operations that can be performed on the data, in the ease of changing or updating the data, in the forms in which output products can be produced, and in the statistical generalizations of the data that can be made.

This report does not discuss the algorithms or computer programs and operations that are required for creation and analysis of a gengraphic data base. It does, however, attempt to place those operations within a rigorous philosophical framework so that the reader can appreciate what he is asking of the system and what he can exp?ct to get out of it. 
The report by Calkins and Tomlinson (1977) is an excellent general guide to the creation and use of geographic information systems. It does not describe any particular system, but it describes practical methods and constraints for system design and use.

\section{DESIGNING A GEOGRAPHIC DATA BASE}

Data that are selected for use by a GIS may be "raw" data in basic form or data that have been processed, mapped, or interpreted in various ways. The creator of the data base must make a number of choices involving tradeoffs among completeness and detail of the data sets to be analyzed, the amount of data manipulation that must be done to answer a user's question, and the amount of detail that is required by the user.

Suppose that a data base is to be designed for evaluating streamflow in the United States. It would be possible to enter mean, minimum, and maximum daily flows for more than 10,000 stream-gaging stations in the United States, some of which have more than 50 years of record. Such a data base would be very large and would be expensive to use. A simpler data base would contain maps showing statistical generalizations of the streamflow characteristics by drainage basin, such as mean, minimum annual, and maximum flow. This data base would be simple and inexpensive to use to answer general questions, but its information would be usable only on a national or regional comparative basis and would not be capable of responding to a user's detailed question about streamflow at a particular point.

We cannot expect any data base to be capable of answering all questions (an old proverb states, "A fool can ask questions that wise men cannot answer"). We can, however, expect that intelligent decisions (and even guesses) can be made as to what questions a data base would be asked. Intelligent decisionmaking requires a thorough knowledge of the actual or potential user community and its interests.

It is customary to visualize a GIS as analyzing a series of data planes, with the capability of analyzing data in a single plane and also of showing the relations among selected sets of those data planes. Data in a single plane may be raw data or the result of previous processing, or they could have been created by the GIS. For example, a data base might contain a plane consisting of digital elevation data. From this layer, additional maps can be constructed, for example, maps showing slope, rate of change of slope, and aspect.

\section{LOGICAL AXIOMS FOR DATA USED BY GEOGRAPHIC INFORMATION SYSTEMS}

Geographic data bases contain individuals, classes, attributes, and statistical ard mathematical generalizations of attributes. Ar individual is a single data point, such as a value at an $x, y$ coordinate, that cannot be logically divided. A class is a collection of individuals. Tro individuals may have the same value and be at different locations, or they may be at the same location and have different values. An attribute is any value, quality, or characteristic that belon $\%$ s to an individual or a class. It may be a name. a numerical value, or a statistical parameter.

Data of any type can be statistically characterized, but in a geographic information system attributes characterize a location or an area because spatial position is of equal importance to the value of the attribute, and indeed is a unique characteristic of the individual.

Analysis of data in a geographic information system requires that the user recognize some basic logical axioms that apply to the data and their relations. Most of the axioms can be considered common sense, but it is worthwhile to make them explicit for complete understanding of the data, their attributes, and their relationships.

A data plane is a collection of features with $x, y$ coordinates; the attribute form's the z-coordinate. The data plane may be coded and displayed in either vector or grid-cell form. In vector form, the data are manipulated and displayıd as points, lines, and areas. In grid-cell form, the data may be visualized as cells of a regular grid, each cell having a value. A data plane may show values in nominal, ordinal, cardinal, or ratio form.

A point is the smallest mappable unit to which a property may be attributed. A line is the locus of all points that have the same attribu+e and within which no point is adjacent to more tr an two other points. An area is the locus of all foints having the same attribute and within which any point may be adjacent to three or more other points.

The four axioms on which our arrument rests are

1. There exists at least one individual (that which exists as a separate and distinct entity). If this were not so, there would be no subject to discuss. 
2. The individual possesses at least one attribute. If this were not so, it would not be an individual.

3. Individuals are distinguishable from each other on the basis of their attributes. For example, there may be many houses in an area, but they are distinguishable on the basis of attributes of size, value, number of occupants, and so forth.

4. Individuals and attributes may be classified into usable categories. The normal principles of logic and symbolic logic are based on the above axioms but do not usually take into account the statistical, temporal, or spatial relations of individuals. The field of geography has implicitly used the principles of logic with relation to place but has not explicitly formulated the rules and principles that allow logical operations to be performed on spatially distributed data. Nystuen (1968) has identified three fundamental spatial concepts in the development of an "abstract geography" but urges that empirical work in the field of geographic analysis remain strong. The three concepts are direction, distance, and connectiveness. Nystuen points out (p. 39) that connectiveness is a topological property of space and that it is independent of direction and distance. All three properties are needed to establish a complete geographical point of view. The concept of connectiveness subsumes the concepts of adjacency, proximity, superposition (vertical connectiveness), and containment.

A number of further axioms are given below with an example of the application of each. The term "data" refers to an attribute of an individual as represented in the spatial data base. The term " $x, y$ coordinate" refers to the spatial position of that individual in the data base. The "individual" may be a point, a line, a grid cell, or a polygon. It is the smallest homogenous unit to which attributes may be assigned.

1. Data at the same $x, y$ coordinate in all data planes apply to that $\mathrm{x}, \mathrm{y}$ coordinate (universal).

2. Data at an $x, y$ coordinate in some data planes may be valid for that $x, y$ coordinate and for some region around that coordinate; the region of influence varies as a function of a radius, a numerically defined region (such as a Thiesen polygon), or a spatial frequency of occurrence.
3. Data at an $x, y$ coordinate in some data planes may be valid for that $\mathrm{x}, \mathrm{y}$ coordinate and for some region defined by a boundary in another data plane (attribute within a region).

4. Data along a straight or curved line of $x, y$ coordinates may be valid for those coordinates and for some region whose bo'undaries are parallel to that line; the region of influence varies as a function of the distance (proximity to a road or to the centroif or edge of an urban area).

5. Data at an $x, y$ coordinate in some data planes may be valid for that $\mathrm{x}, \mathrm{y}$ coordinate, and their relation to the immediately surrounding $x, y$ coordinates is defined in only one or two directions (maximum slope of a surface).

6. Identical data at various $\mathrm{x}, \mathrm{y}$ coordinates in a single data plane are identical (universal).

7. A feature in one data plane may be used to select data within its $\mathrm{x}, \mathrm{y}$ coordinetes from other data planes (masking or "conkie cutter").

8. Varying data may be replaced by uniform data within a boundary (statistical classification or generalization).

9. Data at an $x, y$ coordinate may be characterized by their similarity to or difference from data at neighboring $x, y$ coordinates (filtering).

10. Data at an $x, y$ coordinate or aggregations of data at various $\mathrm{x}, \mathrm{y}$ coordinates may be named (labeling) or ranked.

11. Statistical measures and procedures may be applied to aggregations of data regardless of their $x, y$ coordinates (classification) or to data in different layers at the same location (correlated layers).

12. Data in a neighborhood may be characterized by their spatial relation to a point within or exterior to the data plane (aspect of a surface or intervisibility).

13. Data having uniform attributes may be counted (number, length, area, or spatial frequency).

\section{WHAT IS A CLASS?}

The logic of classes is treated in Werkmeister (1949) and Carnap (1958) as an extension of the calculus of propositional functions. However, in formulating and using the traditional rules of symbolic logic, classes, their values, and the relationships among classes consider only their attributes or functional relationships and not their 
spatial relationships. The traditional rules of propositional calculus and symbolic logic apply to the creation and operation of geographic information systems, but, in addition, the attributes of classes may depend on their spatial shape, their connectiveness to other classes, or to a statistical measure of the attribute of a single class or a group in close spatial proximity.

The principles of symbolic logic in a geographic information system are most efficiently applied to classes of points, lines, and areas. A class is usually thought of as a group of points that may be spatially coextensive and that have the same attributes. However, it is possible, and in many cases quite necessary and useful, to define as a separate class all of the spatially coextensive points in a given class that are within a certain spatial distance from the spatially coextensive points in another class. This can be illustrated by considering the edge of a landmass at the ocean. The land is one class and the ocean is another class. But it is possible to postulate a third classthe shoreline, which is a unique class of coextensive points. We may then define an additional class of land that is within a specified distance of the shoreline, thus creating four useful classes when we started with two. This process can go on indefinitely. Mandelbrot (1977) showed that the class of shorelines is a fractal (a curve without a tangent); that is, between any two points along the shoreline, the line itself may be as short as the shortest distance between the two points or it may be of almost infinite length, depending on the scale and resolution at which it is mapped and portrayed. The question of scale of portrayal of the classes considered by Mandelbrot is relevant to geographic information systems when one is deciding at what map scale to analyze and display the information. It will suffice to say that the length of the line defining the boundary between two classes (or the line defining a class itself) is dependent on the scale of mapping (in cartographically drawn maps and in digital data displayed in a vector format) or on the resolution of the data (for displays of grid-cell or raster-format data). Thus, the definition of a class may depend not only on the attributes of its members, but also on their distribution: a class may be defined as (1) a point with one member and one or more attributes, (2) a line with a number of spatially aligned members, no one of which is adjacent to more than two other members and which must have one or more attributes, and (3) an area with three or more contiguous members which must have one or more attributes.

A geographic data base contains classes with what are usually referred to as " $\mathrm{x}, \mathrm{y}, \mathrm{z}$ coordinates." $\mathrm{X}$ and $\mathrm{y}$ are Cartesian coorcinates which may be related to map coordinates in a given projection, and $\mathrm{z}$ is the value of an attrilute. All data planes have the same system of $x$ and $y$ coordinates, and each one shows a class or classes, each with one or more attributes. ${ }^{1}$ The classes may be indicated on the data plane or described in separate files.

In the strictest sense, any $x, y$ ccordinate has only one z-coordinate or attribute in a single data plane. Common sense tells us, however, that it may have many attributes. For example, the attribute "forest" has a high correlation with "on land," "presence of leaves," and "ability to transpire water."

It is the problem of covariance of attributes that occupies the interpretive mapper and is of particular importance when there is a sratial covariance to be described as well as an attribute covariance at a point.

\section{THE RELATIONS AMONG CLASSES}

The relationship of classes is based on the calculus of propositional functions, with the addition of the spatial-class definitions given previously. The following is paraphrased from Werkmeister (1949), as an explanation of the potulates governing class relations.

\section{Definitions}

1. Universal class $=$ everything $=1$.

2. Null class $=$ nothing $=0$.

\section{Postulates}

1. If $a$ and $b$ are classes, then ther $\epsilon$ is class $a+b$ (logical sum). The logical sum consists of the members that are distributed between $a$ and $b$. This is the logical "or" operation.

2. If $a$ and $b$ are classes, then there is class $a \times b$ (logical product). The logical product of two

\footnotetext{
1There are two other specialized systems that should be mentioned but that are little used at present. The first uses stereoscopic parallax as a fourth coordinate, which allows display in a three-dimensional view of the other three coordinates-two spatial and one an attribute. This has been used, for example, to display magnetic intensity superimposed on a color display of a satellite image. The second involves animation of change in an attribute or in the position of an attribute and is best displayed as a motion picture or video display. A third system could be postulated which would combine both of these, tr 's giving a threedimensional animated color motion picture of attribute change. I know of no system that does this at present.
} 
classes consists of the members that are common to a and b. This is the logical "and" operation.

3. There is class 0 such that $a+0=a$, for any class a. The logical sum of class a and the null class is identical with the class $a$.

4. There is a class 1 such that $a \times 1=a$, for any class $a$. The logical product of class $a$ and the universal class is identical with the class a.

5. If there is a universal class 1 and a null class 0 , then for any class a there is a class $\sim a$, such that $a+\sim a=1$. The logical sum of $a$ class and its negative exhausts the universe of discourse, whereas a class and its negative exclude each other, that is, $a \times \sim a=0$. This is the logical "not" operation.

6. If $a, b, a+b$, and $b+a$ are classes, then $a+b=b+a$. This is the Commutative Law for Logical Sums.

7. If $a, b, a \times b$, and $b \times a$ are classes, then $a \times b=b \times a$. This is the Commutative Law for Logical Products.

8. $a+(b \times c)=(a+b) \times(a+c)$. This is the Distributive Law for Class-Sums.

9. $a \times(b+c)=(a \times b)+(a \times c)$. This is the Distributive Law for Class-Products.

10. There are least two classes, $a$ and $b$, such that $a \neq b$, that is, $a$ is not identical with $b$.

The relationships defined in these postulates can be clarified by the diagram in figure 1 .

- Let the rectangle represent the universal class 1.

- Everything inside the complete circle " $a$ " is included in the class a.

- Everything inside the complete circle " $b$ " is included in the class $b$.

- Everything outside the circle "a" but inside the rectangle is $\sim a$.

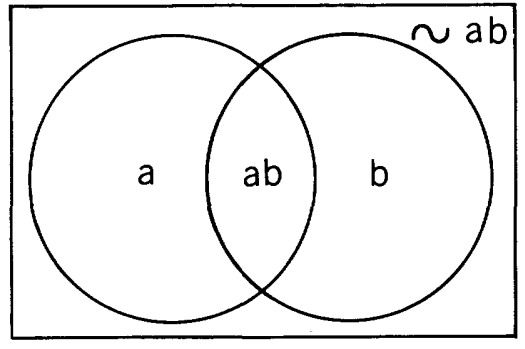

FIGURE 1.-Schematic diagram of two classes in map form.

- Everything outside the circle "b" but in "ide the rectangle is $\sim b$.

- Everything belonging to the total area of the two circles is included in the class-sum $a+b$.

- Everything in the overlapping area of the two circles is included in the class-product $\mathrm{a} \times \mathrm{b}$.

By shading the area of the null class, we can illustrate the product of a class and the null class, as shown in figure 2 .

Other relations and functions can be represented in a similar manner. Once the potulates have been given, it is possible to introc'uce the relation of class-inclusion by definition. Accepting " $\subset$ " as the symbol for class-inclusion, so that " $a \subset b$ " means "class $a$ is included in clas? $b$," we define

1. $(a \subset b)=(a \times \sim b=0)$

2. $(a \subset b)=(b+\sim a=1)$

3. $(a \subset b)=(a \times b=a)$

4. $(a \subset b)=(a+b=b)$

These definitions, in conjunction with the postulates, enable us to derive an indefinite number of principles or theorems of the class "celculus." The following examples are self-explanatory. (We simplify by writing ab instead of $a \times b$.) The symbol "د" means "implies."

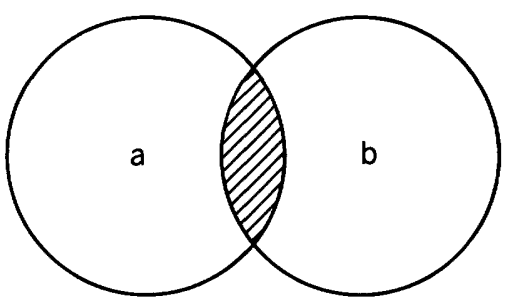

$a \times b=0$

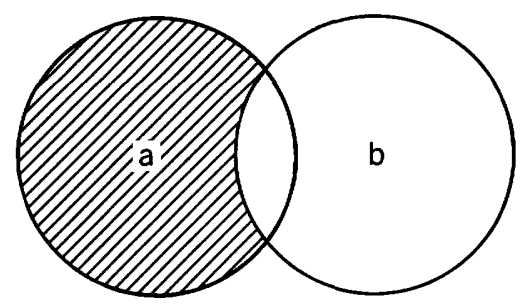

$a x \sim b=0$

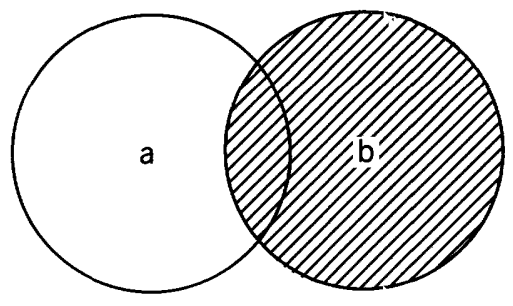

If $b=0$, then $a+b=a$

Figure 2.-Venn diagrams of the logical products of two classes. (From Werkmeister, 1949, p. 435.) 
1. $a b \subset(a+b)$ (from postulates 2 and 1 )

2. $a b \subset a$ and $a b \subset b$ (principle of simplification)

3. $[(a \subset c) \cdot(b \subset c)] \supset[(a b \subset c)]$

4. $[(a \subset c) \cdot(b \subset c)] \supset[(a+b) \subset c]$

5. $[(a \subset b) \cdot(a \subset c)] \supset(a \subset b c)$

6. $[(a \subset b) \cdot(a \subset c)] \supset[a \subset(b+c)]$

7. $[(a \subset b) \cdot(b \subset a)] \supset(a=b)$

8. $\mathrm{a} 0=0$

9. $[(a \sim b=0) \cdot(b \sim c=0)] \supset[(a \sim c)=0]$

10. $[(a c=0) \cdot(b c \neq 0)] \supset[(b \sim a) \neq 0]$

Although the Venn diagrams used by Werkmeister (fig. 2) are meant to illustrate symbolically the logical relations among classes, they can easily be used to illustrate also the spatial relations among classes. If we consider figure 3 , we can visualize the rectangle as the base map (or base data plane) in a geographic information system. In that figure, $a$ is an area class while the map area outside the class is null. It is then easy to see that the methods of overlaying mapped classes in separate data planes is an exercise in logic which is carried out by Boolean logic operations in a computer following the previous axioms and the postulates of symbolic logic. These axioms and postulates are usually described as the logic of functions "and," "or," and "not." The function "and" applied to a and $b$ in figure 2 would result in a map of the total areas of $a$ and $b$; the function "or" would result in a map of ab; and the function "not" would result in a map of the areas of a and b that are not common to each other. These areally coextensive classes may be represented in a geographic data base either by vectors showing the boundaries of the classes or by grid cells showing the area of the classes. Conventionally, "+" means "or," " $x$ " means "and," and " " = not.

The "and" function operates in a computer system according to the following truth table:

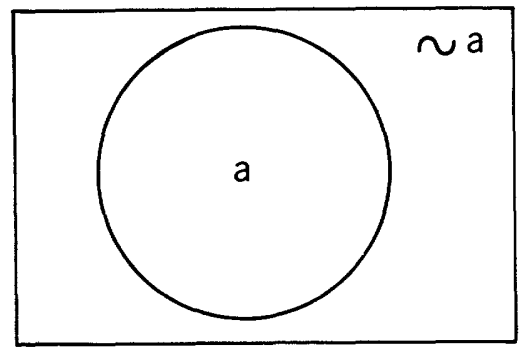

a $\times 1=a$

FIGURE 3.-The null class.
If $\mathrm{A}$ and $\mathrm{B}=\mathrm{C}(\mathrm{A} \times \mathrm{B})$,

\begin{tabular}{c|c||c}
$\mathrm{A}$ & $\mathbf{B}$ & $\mathbf{C}$ \\
\hline 0 & 0 & 0 \\
0 & 1 & 0 \\
1 & 0 & 0 \\
1 & 1 & 1
\end{tabular}

The "or" function operates according to the following truth table:

If $\mathrm{A}$ or $\mathrm{B}=\mathrm{C}(\mathrm{A}+\mathrm{B})$,

\begin{tabular}{c|c||c}
$\mathrm{A}$ & $\mathrm{B}$ & $\mathrm{C}$ \\
\hline 0 & 0 & 0 \\
0 & 1 & 1 \\
1 & 0 & 1 \\
1 & 1 & 1
\end{tabular}

The "not" function operates according to the following truth table:

If $\operatorname{not} A=B(\sim A=B)$,

\begin{tabular}{c|c}
$\mathrm{A}$ & $\mathrm{B}$ \\
\hline 0 & 1 \\
1 & 0
\end{tabular}

These functions can be concatenated into more complicated but useful ones, such as the EQV functions:

$\mathrm{C}=(\mathrm{A} \times \mathrm{B})+\sim(\mathrm{A}+\mathrm{B})$

\begin{tabular}{c|c||c}
$\mathrm{A}$ & $\mathrm{B}$ & $\mathrm{C}$ \\
\hline 1 & 1 & 1 \\
1 & 0 & 0 \\
0 & 1 & 0 \\
0 & 0 & 1
\end{tabular}

A Venn diagram can be applied to spatial data without consideration of the spatial relations to promote understanding of the possible and impossible (or unlikely) combinations of data. Varnes (1974) demonstrates in his figure 23 the relation among slope, firmness, and thickness of geologic units in order to determine their suitability for engineering purposes. This figure, and indeed his entire report, should be consulted for a rather full explanation of map logic and the attributes of map units. His explanation of the logic of map units is based largely on areally coextensive units and only slightly on point and line data, which are of major importance in digital geographic systems. 
The logical relations of spatial position (fig. 4) may be explained as follows:

1. Adjacency: Class $A$ is always adjacent to class D (for example, water is always adjacent to land).

2. Proximity or connectedness: Class A is always within a certain distance of class $D$ but is never adjacent to it (for example, end members of a continuum, such as vegetation density).

3. Superposition (z direction): Class A always lies above class $\mathrm{D}$ (for example, one layer of rock always overlies another layer).

4. Containment: Class A always lies within class $D$ (for example, the hole in the doughnut is always surrounded by the doughnut).

A classification must be logical. For example, one cannot logically establish classes for a mapped area such as (1) wooded, (2) urban, (3) recreational, because a wooded site may or may not be recreational and an urban site may or may not be wooded. It would be necessary to classify each area of the map as wooded or not wooded, urban or not urban, and recreational or not recreational and then use logical rules to show the relations of the three maps.

Varnes (1974) notes four operations that are performed on maps: generalization, selection, addition and superposition, and transformation. Each of these operations must conform to the log-

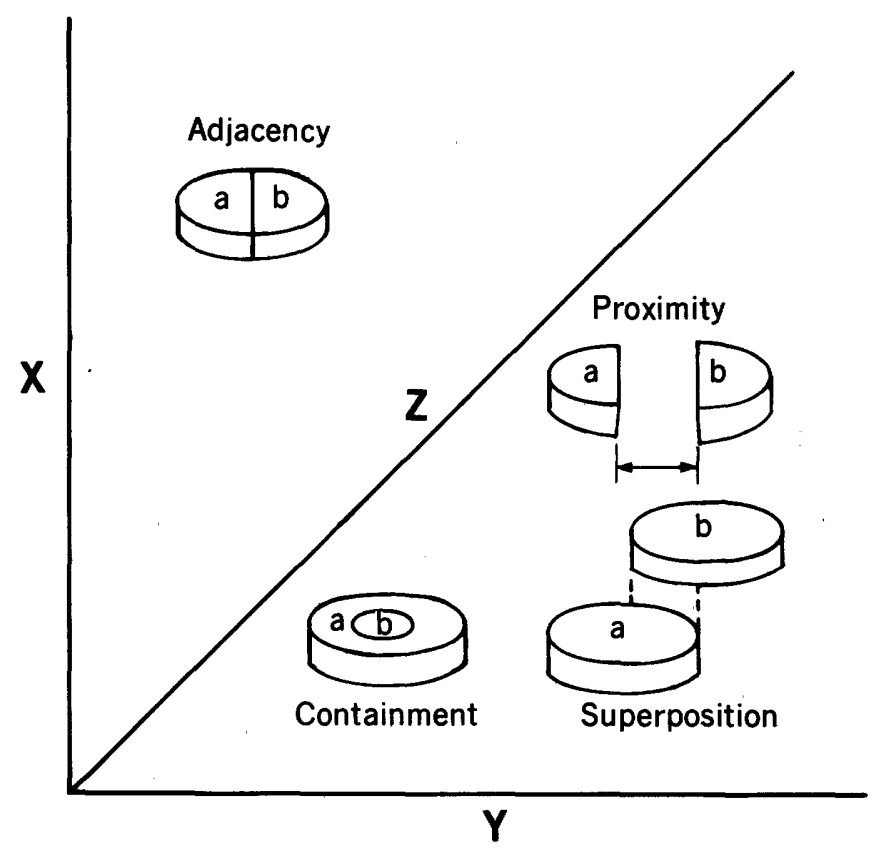

FIGURE 4.-Logical relations of spatially located classes. ical principles previously outlined. The forformance of these operations on digital data is done by computer programs. An important point to keep in mind is that some of these operations can be performed on data before they are put in map form, such as tabular attribute data sorted and categorized by a data-base management system. A decision must be made for a given ar?a as to what to map and what not to map. This is a process of selection. A decision must also be made, for any mappable unit, as to what attributes to describe or measure in detail and which to infer on the basis of attribute covariance and which not to. This is the process of generalization. It is not possible for the individual who makes an original map (from detailed field data) to predict all the questions the user may eventually ask about the area. He can only map, to the best of his ability, the features he believes will be useful; in the mapping process, he selects and generalizes. The product of his field mapping becomes the input to a digital data base. If his map has detailed quantitative data, the digital data base will be detailed and quantitative. If not, it won't. If a severe process of generalization has occurred before the map is digitized, the original data cannot be rocovered and the map may be useful for only a single purpose. An extreme example would be a set of map data on soils, soil permeability, slope, depth to the water table, and other factors used to create a "stoplight" map of suitability for waste disposal (that is, the map would indicate that a location either is or is not suitable.) If the stopligh $t$ map is the only map stored in the data base, it is usable only for the purpose for which it was designed; it cannot be decomposed into its parametric attributes. If, however, the basic attribites are stored at the level at which data are collected in the field, the final interpretive map can be recreated with the same or different generalization criteria and, in addition, other derivati`e maps can be created from the same basic data for other purposes. For this reason, it is always desirable to store the data in as primitive a form as possible. Derivative maps can also be stored for later use, but they should supplement, not replace, basic data. The processes of addition and superposition follow the logic of the Venn diagram proviously explained. One map can be superimposet on another, a program can select the areas of common attributes from two maps, maps can be added together, and a program can select only the minimum or maximum values occurring in two maps. 
Maps may be transformed by changing the character of their symbols or the means of presentation. The original data, such as a set of points with values on a digital map (for example, elevations on a geologic horizon), may be contoured or a mathematical surface may be fitted to map the elevation of the horizon at any point in the map. Some transformation operations may be performed consistently and efficiently on a digital map to create entirely new maps. A map of roads may be operated on by a proximity mapping program to display all areas that are within a given distance of the roads. This proximity map may then be used as a mask to show only certain features in the proximity area. The use of a Venn diagram can be illustrated by an example from the field of ground-water analysis. In a coastal area, high pumpage of freshwater from an aquifer will result in a decline of water levels in the aquifer and may result in drawing saltwater into the aquifer. The situation may be illustrated by a Venn diagram (fig. 5). Three conditions-well pumpage, water-level decline, and salt concentration-are each described in two classes, low and high. The relations of the two conditions of the three classes are shown by shading. The classes in this case obviously have a high covariance, but the degree of covariance will ultimately depend on their spatial relationship.

The two extreme cases are (1) when pumpage is low, water-level decline is low and the salt concentration of the water is low (striped area), and (2) when pumpage is high, water-level declines are high and the salt concentration is high (black area). The latter situation occurs if wells are near

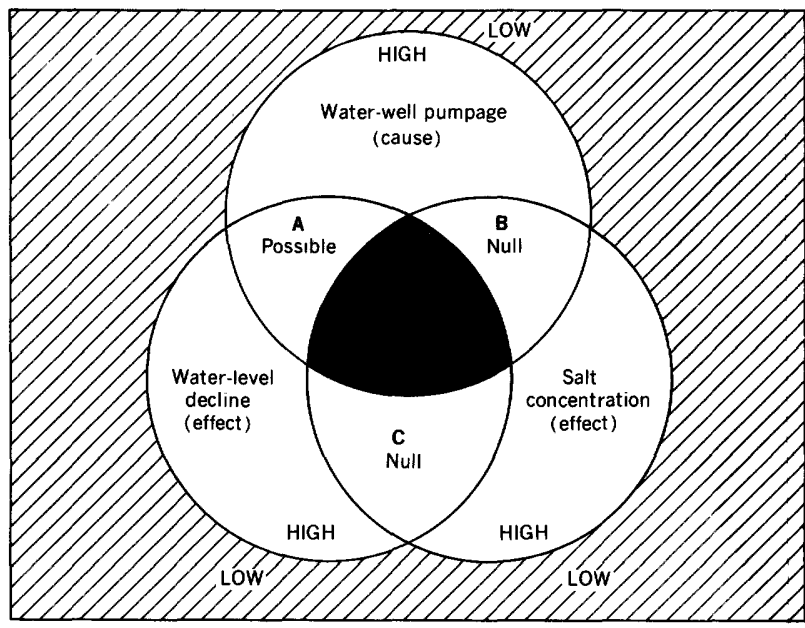

FiguRE 5.-Venn diagram showing relations among waterwell pumpage, decline of water level, and salt concentration of water. the coast, where it is relatively easy for seawater to gain access to the aquifer. Section A (pump $\times$ decline $\times \sim$ salt) represents an area where high water pumpage causes high water-level declines but that is far from the coast so that there is no increase in salt concentration. Sections B ( pump $\times$ salt $\times \sim$ decline) and C (pump $\times$ salt $\times$ decline) are null classes; that is, they cannot exist because pumpage cannot result in a high salt concentration without high water-level decline (B) and there cannot be a high water-level decline and high salt concentration without high pumpage (C). Pumpage may be represented on a map at one or a number of points, and water-level declines and salt concentration may be represented by areas whose size, shape, position, and boundaries depend on the influenc? of the point pumpage sources. This illustration, then, shows the importance of both the logical and the spatial relationships of data and classes that can be used in geographic information systems.

Each of the three attributes in the above example is classified into only two categories, high and low. Either the person who puts the data into the system or the user of the data must decide on the number of categories and the boundaries between them. This is where the trouble really lies-in defining categories in a continuum of data points. The water-well pumpage in the example may range from 10 to 5,000 gallons per minute. Is the category "high" to be above $100,1,000$, or 3,000 or some other number? The same principles and questions apply to the water-level decline and the salt concentration. Thus the boundaries of each of the data sets (and their intersections) are really fuzzy and of various widths, not dis?rete lines as shown in the diagram. Geographic information systems operate best on discrete data in welldefined categories. It is the task of the analyst to determine how the original data car be best categorized when it is entered into a data base. In many cases, categories are either universal classes or null classes. For example, one category of land use might be "forest land." In one data plane of a geographic data base, an area would be displayed as either forest or nonforest. For many purposes it might be more useful to have the data classified by percentage of forest in grid cells or polygons by 10 -percent intervals. This would allow some manipulation around the mean of the forest cover, and displays could be made of the standard deviation from the mean of other useful measurements. Jupp and Mayo (1982) present an example from Landsat image analysis in which 
an image is classified into several categories and each grid cell is then classified further into one of several categories representing its deviation from the mean of its class. This highly useful display allows the heterogeneity of individual classes, as well as their mean attributes, to be portrayed.

These problems of classification, categorization, and boundary definition may be solved (or at least better understood) by considering the classes we deal with as fuzzy sets rather than as examples of two-valued logic or Bayesian probability statistics. Fuzzy set theory is, at the time of this writing, the subject of more than 2,000 papers and books since Lofti Zadeh introduced the subject in 1965 (Zadeh, 1965). I do not intend here to exhaustively discuss the theories and applications, but simply to indicate the basis of fuzzy logic and to suggest that it may become a powerful tool both in the analysis of spatial data and in our understanding of the data and their relationships.

The term "fuzzy system" may be considered to cover the "whole field of imprecisely described systems" (Negoita, 1981). A key to the understanding of fuzzy systems is the word "described." It implies that man's understanding of a system is as important as the precise measurement of individual observations and parts of a system. Imprecision may be a function of measurement accuracy, or it may be a function of the description of the system. A particular feature or concept may be represented by a fuzzy set. Paraphrasing Negoita (1981), we may select the concept of depth of a water body to illustrate the thinking. Let $[0,1]$ act as a unit interval which is a set of real numbers between and including 0 and 1 . We may select water at the surface to be represented by 0 and a depth of 1,000 feet to be represented by 1 . We may now try to assign a specific depth measurement, say 195 feet, to a portion of the $[0,1]$ interval with the fuzzy terms "very shallow," "moderately shallow," "shallow," "moderately deep," "deep," and "very deep." This is done by assigning a given measurement a membership in the $[0,1]$ set. This is quite distinct from the probability relationship. This way of thinking and analysis allows us to cope with such fuzzy concepts as near and far, tall and short, steep and gentle (slopes), high and low, and old and young. The fuzzy system concept then allows us to cope with logical relations (which themselves may be fuzzy sets) in a manner quite different than the manner required with Boolean logic, which demands a two-valued logic in which a given observation either is or is not a member of a given set.
The fuzzy system concept may be illustrated by returning to the previous example of groundwater analysis in which water pumpages, waterlevel decline, and salt concentration were defined as either high or low, with fixed (but numerically undefined) boundaries. It would now be possible to define the grade of membership of any given observation of each of the three factors in the fuzzy set from high to low. This concept of the fuzzy set and the membership of an object (or a measurement or relation) allows both perception and linguistic description. We can then operate with a description of moderately high pumpage or fairly low water-level decline without the need to specifically and numerically define the values of each. The importance of this concept and method of operation can be seen when we must deal, in a geographic information system, with questions that are not precise (although the data may be highly precise). With the proper data base, we could ask such questions as "Where are all the areas where a geologic formation subject to landslides occurs near roads?" to determine where there is a risk of landslides damaging highways. Figure 6 is a simple example of this type of analysis. By producing a corridor along roads, dividing that corridor into arbitrary but fuzzy levels of proximity to the roads, and applying the gradient corridor only to the landslide-susceptible formation, the result is a map that qualitatively expresses the hazard to the roads.

The use of fuzzy sets and fuzzy algorithms should be considered for application to geographic data bases and should also be considered for inclusion in artificial intelligence methods for geographic information systems. Much additional research is needed on this subject.

Two other common situations occur in map analysis by a geographic information system that are not as easily handled as is the case of areas with attributes. They are the cases of point data and line data. A common example of point data is a water well for which a number of attributes are available such as its depth to water, the elevation of the water surface, the depth to the bottom of the waterbearing formation, the saturated thickness of rock, and numerous measurements of dissolved constituents. How can these attributes be mapped? Figure $7 \mathrm{~A}$ illustrates one common method, that of constructing a Thiessen polygon on the basis of an irregularly spaced set of data points (wells) shown on a map. Lines are drawn from a well to each of its neighboring wells, the lines are bisected, and the midpoints of the lines 


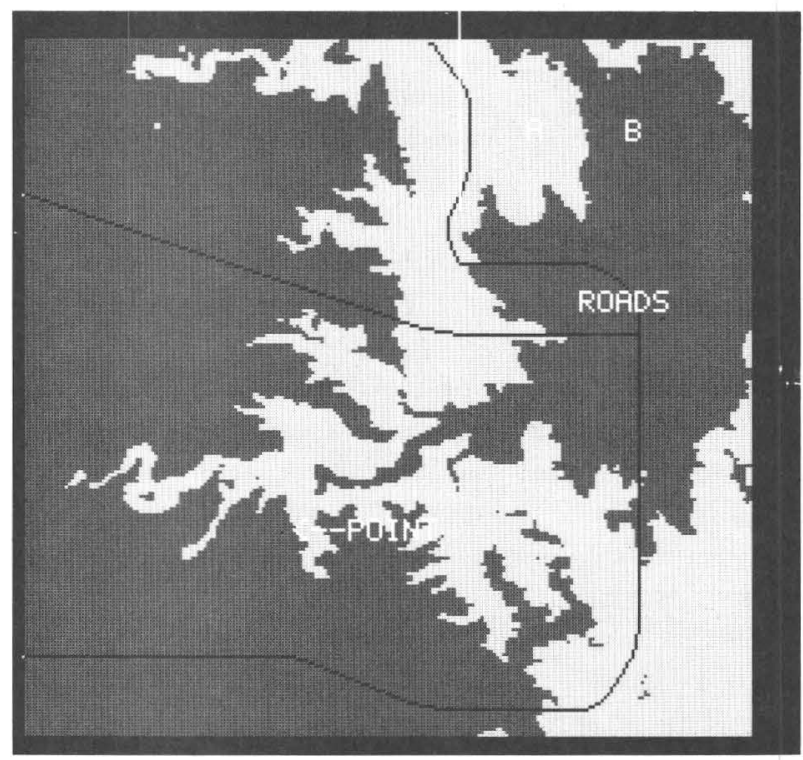

A. A hypothetical map shows two geologic formations (A and B), roads, and a point. Formation A is susceptible to landslides; formation B is not. The landslide danger to the road is inversely proportional to the distance from the road. This distance in formation $\mathrm{A}$ is to be mapped.

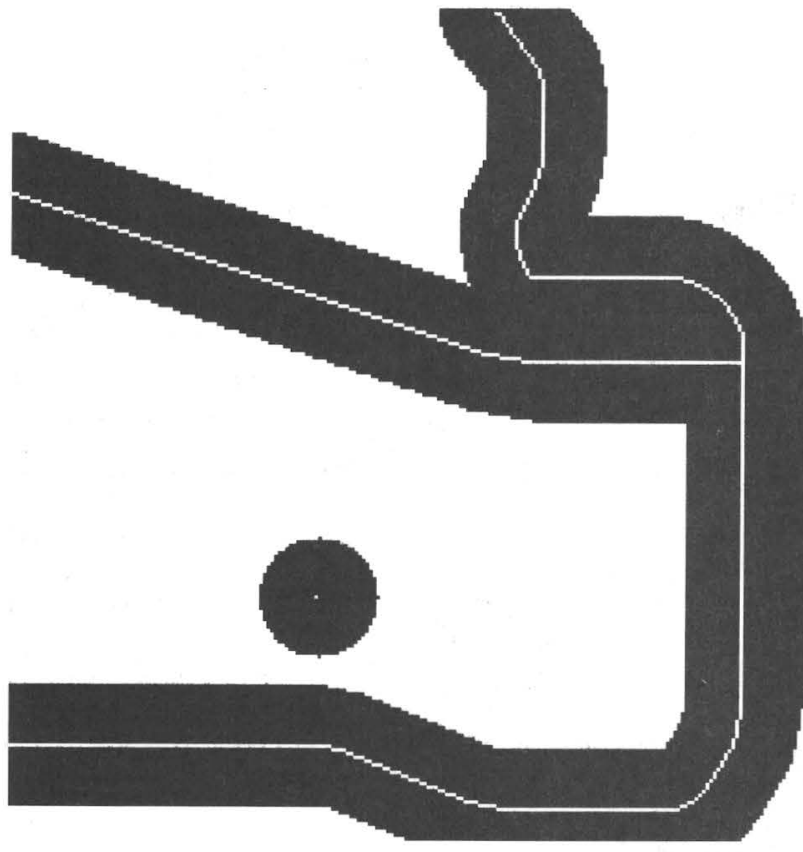

$B$. A corridor 16 pixels wide is mapped around the roads and the point. This is a normal mapping method, but it assumes that features within the corridor are constant.

FIGURE 6.-Gradient proximity mapping and masking.

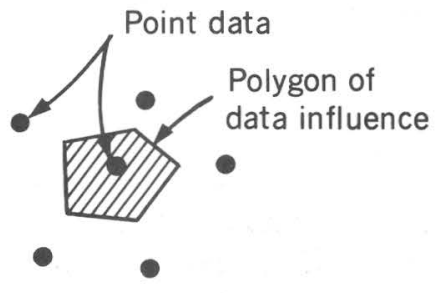

(A)

FIGURE 7.-Spatial representations of the influence of point data. $A$. Data at irregularly spaced points may be converted to polygons by the Thiessen polygon method. Each point then represents the value of the polygon. $B$. A measurement within a polygon whose perimeter is described by other measures may represent the entire polygon area. A point measurement may also represent the mean (or other statistical
Polygon of
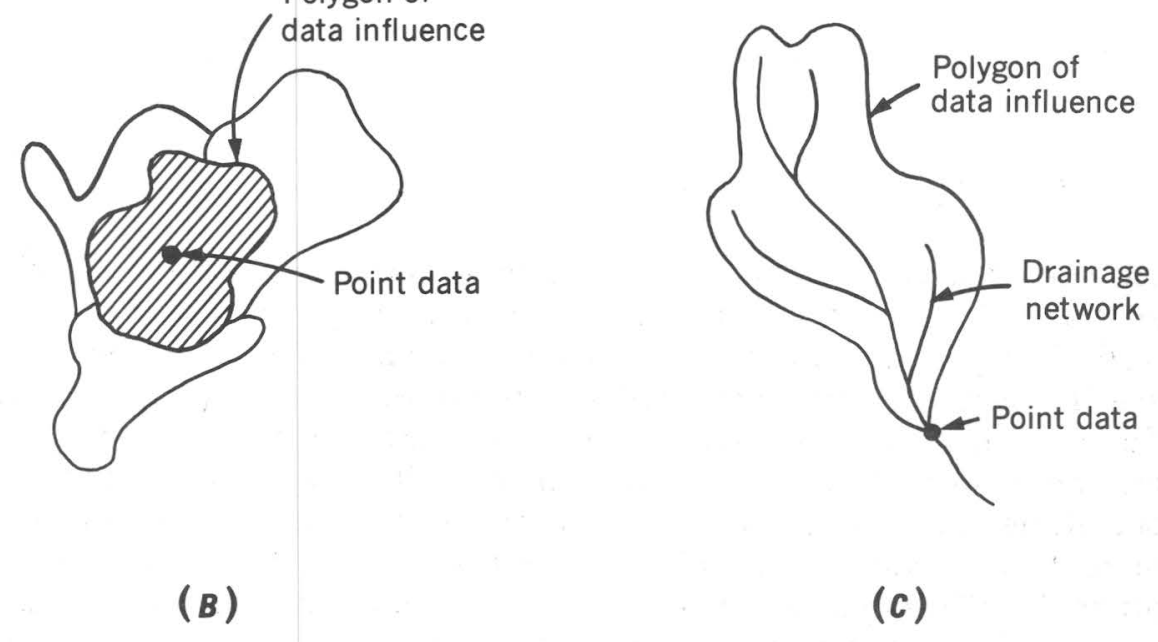

(c) measure) of data of a mass of points in the polygon. C. A point measurement at the edge of a polygon represents the entire polygon, for example, a streamflow measurement representing the drainage basin. This is a special case of $(B)$, and the data may be realigned to a point at the centroid of the polygon for subsequent analysis. 


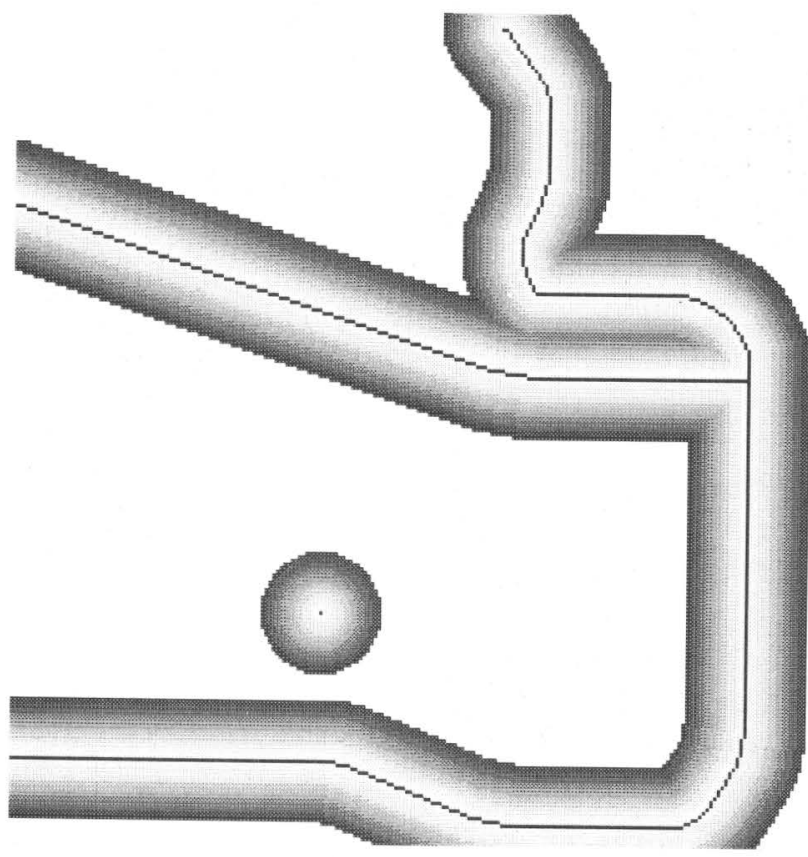

$C$. A corridor is mapped along the roads and around the point to a distance of 16 pixels. The brightest area, adjacent to the roads and point, is the area of maximum hazard. Away from the roads and point, the corridor darkens to the edge of the hazard zone, the area of least hazard.

FiguRE 6.-Continued
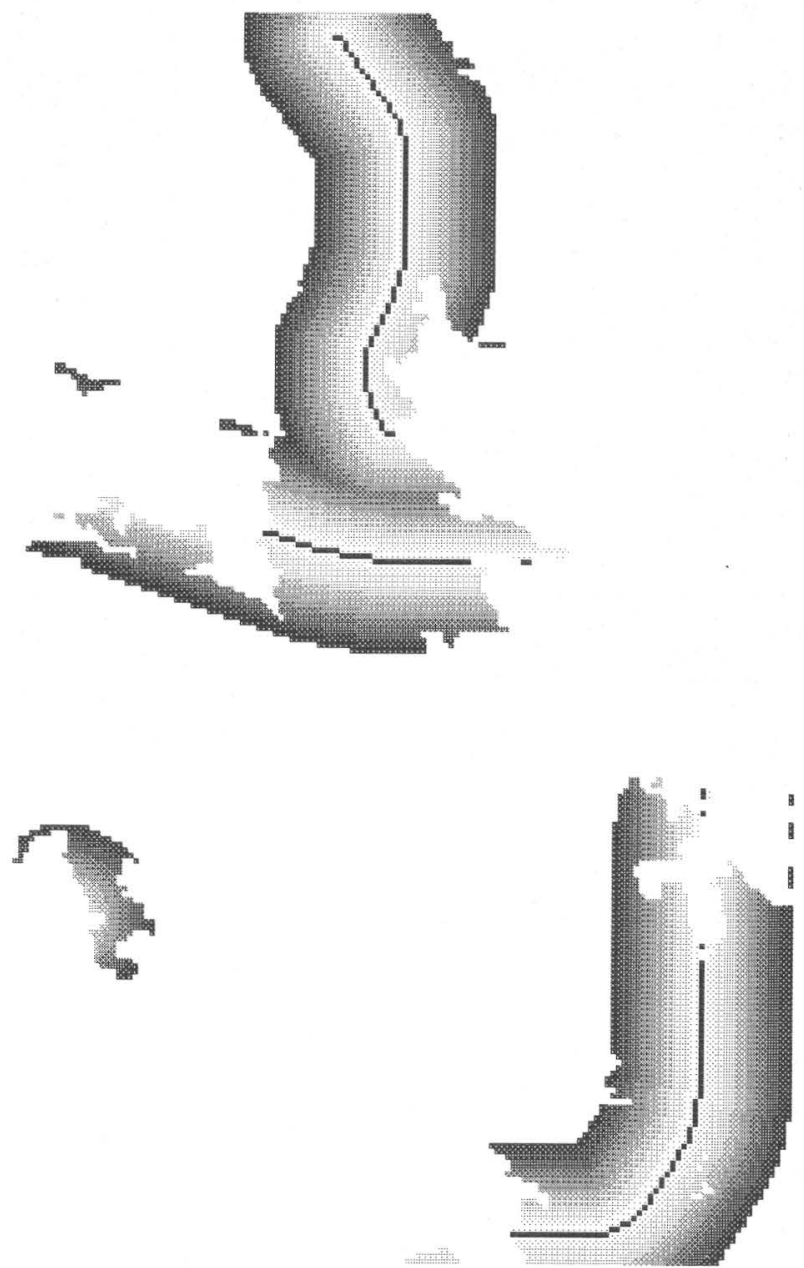

$D$. The hazard zone is used to mark only the map area of formation $\mathrm{A}$ and shows the gradient of the danger zone only where formation A occurs.

with the amount of water consumption measured in the county assigned as a value to the entire county, as shown in figure $7 B$. A special case of the point-data polygon assignment occurs when the point data are on the boundary of the polygon, as shown in figure $7 C$. This occurs where data are taken at a stream-gaging station on a drainage network and the data at the point represent the integration of upstream attributes throughout the drainage basin. Thus, the mean annual flow in cubic feet per second per square mile can be assigned to the polygon of the upstream basin (or to its centroid) and the basin can be distinguished from adjacent drainage basins. Assigning data in this manner can lead to illogical boundary conditions, such as a sharp break in runoff per unit area, which does not really occur in nature. On 
the other hand, assigning the data to the centroid and then contouring can cause loss of mass balance at the gaging station.

The most difficult type of data to handle in a geographic information system are the data represented by a line with changing attributes along its length. A common situation is shown in figure 8. Data were collected at a point along a line, in this case, along a reach of a main stream between two tributary inflows. A system must be capable of assigning the data at the point to the entire line but not to the bordering areas. This can be readily handled when the line is represented by a series of labeled vectors, which really means labeling a set of shorter lines with discrete but

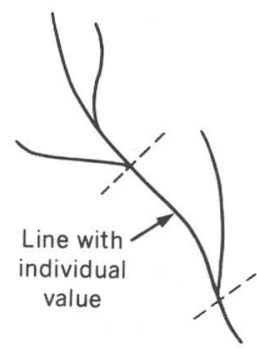

(A)

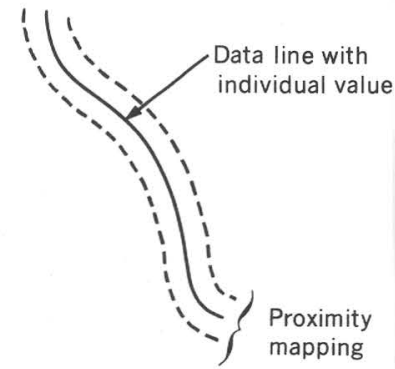

(B)

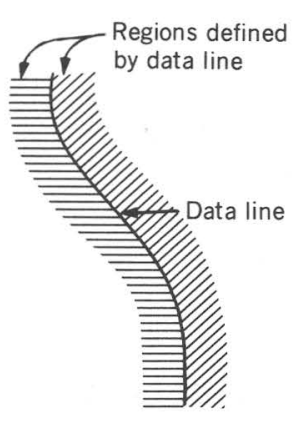

(c)

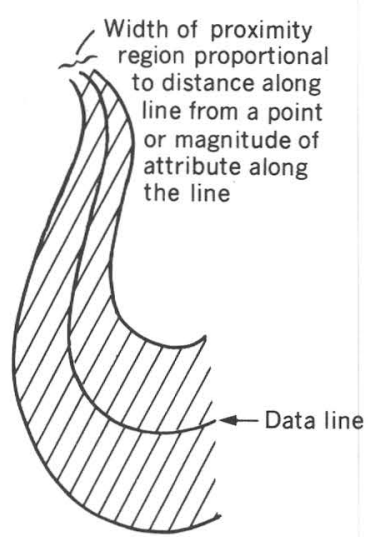

( 0$)$
FIGURE 8.-Spatial representations of the influence of data represented by a line. $A$. A point may represent data influence between two points along a line, such as a stream, but may not be valid for any bounding region. $B$. The line may be mapped an equal distance on each side to show that its influence extends to that width. $C$. A line may define a region on either side, such as "more than" or "less than" the value of the line. $D$. If the line has a varying magnitude in a direction, the proximity (or influence) may be proportional to the magnitude of the influence. differing attributes. In the case of a grid-cell system, the network line is composed of a contiguous line of grid cells and the aggregate of the grid cells is labeled as a class with the attribute of the data point. A second situation is illustrated in figure $8 B$; in this situation, proximity mapping creates a class bounded a given distance from a line, such as mapping of all the areas within 1 mile of major roads. This is readily accomplished in both vector and grid-cell systems.

The third situation, in figure $8 C$, is one in which the line does not represent basic data but is simply a boundary between two regions or classes. In a vector system, the line would be labeled with the classes on either side. In a grid-cell system, the line would not exist of itself but would be represented solely by the juxtaposition of the two classes.

The last situation, shown in figure $8 D$, does not involve analysis of the data, but only display. Nevertheless, such a representation can be important in showing the magnitude of an attribute of a line that changes in a manner proportional to some function of the length of the line. It could, for example, represent the increase in mean annual flow of a river in a downstream direction. The author does not know of an algorithm for accomplishing this display.

How does a user frame questions so that they can be answered by a geographic information system? A user with a need for information on a specific area may use a geographic information system to query a geographic data base. In a generic sense, the user may ask one of two questions: (1) For a given area of land, what are its attributes? and (2) For a given use of land, which areas have the proper attributes? The first question is readily answered by displaying, in map form, the various data planes in a geographic data base to allow review of the attributes of the land. The information gained by this approach relies heavily on the way in which the data are stored and classified in the system. A simple geographic data base for an area in the Western United States might, for example, contain the following data planes:

1. Elevation of the land surface, in 200-foot intervals.

2. The slope of the land surface, in intervals of 5 percent.

3. A vegetation map showing barren land, desert shrub, hardwoods, and conifers.

4. A land-use map showing rangeland, cropland, and urban land. 
The user can display all of these in turn and develop a perception of the type and condition of the land: it is generally flat or steep, it is predominantly rural or urban, it is largely desert or wooded, and so on. The development of such a perception is important to the user because it allows him to compare, in general terms, many different areas.

The second type of question is more difficult to answer. The answer depends heavily on the classification of information in the system and also very heavily on the way in which the user asks his questions. The system contains the attributes of the land, classified in a certain manner, but the user must understand the manner in which the data are classified in order to frame a specific question. In the example given above, it would be of no use for the user to ask the question, "Where are the areas that are suitable for diversion of water for irrigation?" because the system as described contains no information on water. Although this may seem at first glance to be not only obvious but trivial, it is not. The creator of the geographic data base creates it for a purpose (either explicitly or implicitly) by deciding which information to put in and which information to leave out. He also decides how to classify or group the information that is in each data plane. This process automatically limits the questions that can be asked. It is obviously impossible to put in all the possible data on an area-and it is equally impossible to anticipate all the questions about the area that someone may wish to ask. The user, therefore, must be able to frame his question within the boundaries and parameters of the data and the means of manipulating it. A logical question to be asked, in the above example, could be, "What areas are the best sites for a vacation home in the area?" The question may be within the bounds of the data, but it must be made more specific to cope with the parameters of the data. The reframed question might well be, "Where are the places in this area where the elevation is above 8,000 feet (for coolness and comfort), where the slope is less than 5 percent (for ease of home construction), where there are conifers (because I like such a setting), and where there is little development (more than 5 miles from the nearest farm or town)?" With these bounds that relate to the stored attributes, the question can be answered. The answer will be a map showing a limited number of places that meet the criteria. The user can then explore these areas to pick a specific site by gathering further information to answer such questions as, "Is there a good scenic view from the site?" or "Is the site for sale?"- pertinent questions whose answers are needed for final selection, but ones that cannot be answere by the data in the particular geographic data base.

The use of logical relations for mapping with a digital geographic information system can be demonstrated by starting with the question, "In a given river basin, where are the liquid waste disposal sites that are in the same grid cell as water bodies or are adjacent to grid cells containing water bodies?" This exercise, though intuitively simple, will be described in some detail to show the logic that must be used.

For the river basin, we initially have tl ree digital maps: (1) the outline or area of the drainage basin, (2) the water bodies (lakes and striams) in the basin, and (3) the location of waste sites in the basin. We thus have 3 two-valued sets: (1) basin or not basin $(B \cdot \sim B),(2)$ water body or not water body $(\mathrm{W} \cdot \sim \mathrm{W})$, and (3) disposal site or not disposal site (D- $\sim \mathrm{D})$. In this example, the grid-cell size is 1 kilometer square. A grid cell is labeled a "disposal site" if a site occurs anywhere within the grid cell; the same is true for water bodies.

The water-bodies set is treated with a proximity mapping program to map all grid cells that are adjacent to water bodies. This creates a fourth data set $(\hat{W} \cdot \sim \hat{W})$. We can now consider which sets to map and which intersections (logical products) of the sets to map to show their relationships. The data sets are now

1. The area of the basin (B)

2. (a) Water bodies in the basin $(W \times B)$

(b) Grid cells adjacent to water bodies in the basin $(\hat{W} \times B)$

(c) Grid cells far from water bodies in the basin $\sim(\hat{W} \times B)$

3. Waste disposal sites in the basin $(D \times B)$

The intersections (logical products) of the data sets are

1. (a) Grid cell with water body and waste site $(\mathrm{W} \times \mathrm{B}) \times(\mathrm{D} \times \mathrm{B})$

(b) Grid cell with water body and no waste site $(\mathrm{W} \times \mathrm{B}) \times(\sim \mathrm{D} \times \mathrm{B})$

2. (a) Grid cell adjacent to water body with waste site $(\hat{W} \times B) \times(D \times B)$

(b) Grid cell adjacent to water body with no waste site $(\hat{W} \times B) \times(\sim D \times B)$

3. (a) Grid cell far from water body with waste site $\sim(\hat{W} \times B) \times(D \times B)$

(b) Grid cell far from water body with no waste site $\sim(\hat{W} \times B) \times(\sim D \times B)$ 
To answer our original question, the sites are $(\mathrm{W} \times \mathrm{B}) \times(\mathrm{D} \times \mathrm{B})+(\hat{\mathrm{W}} \times \mathrm{B}) \times(\mathrm{D} \times \mathrm{B})=(\mathrm{W}+\hat{\mathrm{W}}) \times \mathrm{D} \times \mathrm{B}$

The data sets and their intersections can be represented by a Venn diagram (fig. 9) which shows the logical placement of each data set and the sets' intersections. Three sets and three intersections of sets result as usable products. The Venn diagram aids consideration of all the sets, places them in their correct relations, and provides a graphic means of considering the sets and intersections to be portrayed on a map.

Figure 10 shows the basic data sets in map form in a two-valued or binary form. In each map, the set is black and the negative of the set within the river basin is gray $(a \cdot \sim a)$.

The intersections of the sets are also shown in figure 10. Assume that a basic data set shows all the waste sites in a digital form, with the waste sites having values of 1 and the background having a value of 0 . A second set has all the water bodies with a value of 1 and the background a value of 0 . An "and" (equivalent to the intersect operation) program compares the two data sets and produces an output map in which a grid cell is given a value of 1 only if that cell has a value of 1 in both data sets. This creates a map showing all waste disposal sites within grid cells containing water bodies $(W \times D)$. A similar method is used for the other relations of waste sites and grid cells.

The total combination of the basic data sets and their relations is most clearly shown in color. Fig-

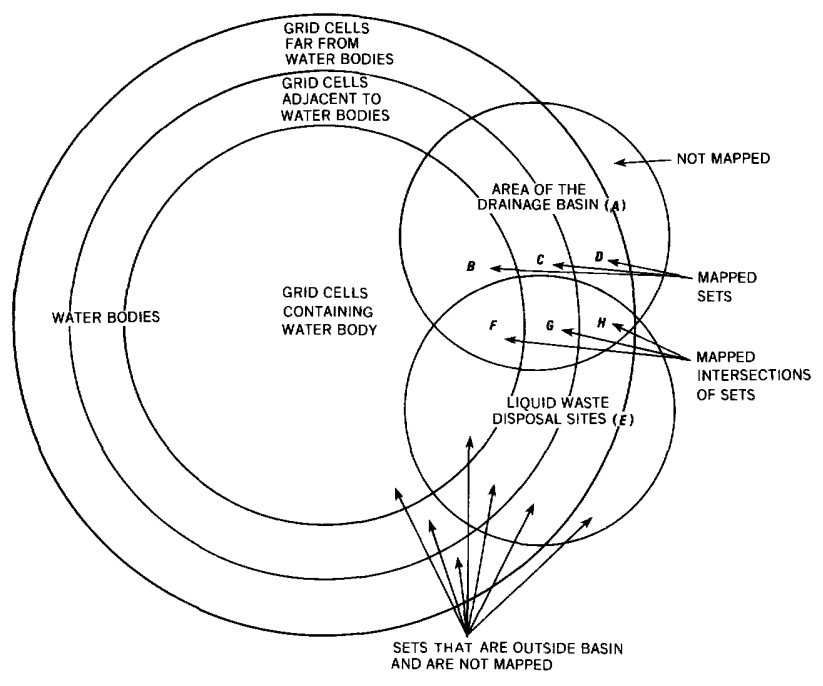

Figure 9.-Venn diagram of mapped sets and intersections of sets for water bodies and disposal sites in a river basin. Letters refer to the mapped sets and intersections in figure 10. ure 11 shows the sets and their relations in gray shades. The logical relations used to create the final map are not evident at first glance, and thus the creator of the map should ensure, by means of the Venn diagram, that the logical relations are correct and that all sets and intersections of interest are included and correctly portrayed. By expressing all operations in logical notation, that correctness of the result can be demonstrated mathematically.

Other logical relations may be analyzed and portrayed in a similar manner if so desired.

Hofstadter (1979, p. 297) states, in referring to the flexibility or rigidity of computers:

One of the major goals of the drive to higher lovels has always been to make as natural as possible the task of communicating to the computer what you want it to do. ... V' think what most people use computers for, you realize that it is to carry out very definite and precise tasks which are too complex for people to do. If the computer is to be reliable, then it is necessary that it should understand, witr out the slightest chance of ambiguity, what it is supposed to do.

The user of a geographic information data base and system usually does not undorstand, and probably does not need to understand, all of the operations that take place within the computer system when it is trying to formulate an answer to his question. But it is important for him to understand how the data is categorized or classified and whether it relates to the question he is trying to have answered. In turn, it is the task of the applications programmer to have a basic understanding of the types of questions the user may ask and to be able to write the programs thet can provide the answers.

Thus, there is a translation proklem between the human language in which the questions are framed and the machine language in which the questions are answered. It is in this translation area that geographic information systems will have their greatest problems-but it is also the area where there are the greatest opportunities for making the systems truly usable. reliable, and understandable by the users. It is usoful to be able to express, in symbolic language, what logical steps need to be followed to process the data to achieve a desired map. If we cannot clearly express ourselves, how can we expect a computer to figure out what we mean?

Two types of display may result from the combination of data by a geographic information system. The first is the result of the operation of some principle upon the data. The principle may be a mathematical formula expressed as an algorithm and program, and its results may not be intu- 
itively predictable in magnitude and type from a simple inspection of the (original revised) data. The second is a simple combination of two or more types of data which, when displayed in a pictorial or cartographic form, convey an impression to the viewer of the relations of the data and which is designed to create a psychological reaction to the combined data. The former type of display is "scientific" in that it attempts to discuss the relations among data elements through a process of mathematical logic (modeling) which is not a result of the preconception of the investigator but which is solely the result of the testing of a hypothesis. The display of the results of a model is done in such a way that the relationships are clear and explicit and are not influenced by any constraints outside the model itself. The latter type of display is "propagandistic" in that it portrays relations among data elements in such a way as to influence the viewer to perceive them in the same way as the creator. An example of this is the portrayal on a map of areas where ground water may be susceptible to pollution from industrial waste. Such a map may portray in red the areas that are highly susceptible, in yellow the areas in which caution should be used in waste disposal, and in green the areas where waste may be safely stored. The impression created by such colors on a map (often called stoplight maps) reflect the conclusions of the creator of the map and may be based on less than totally accurate or less than complete data. The scientific portrayal of the data elements and their relationships would perhaps result in a map showing three categories: (1) areas where the water table is deep and the soils are of very low permeability, (2) areas where either the water table is deep or the soils are of low permeability, and (3) areas where the water table is shallow and the soils are highly permeable (note the necessary use of fuzzy terminology.) This would allow the viewer to draw his own conclusions on the basis of the data or to explicitly or implicitly add his own knowledge to the available data to come to a conclusion as to safety. A fairer way to present the information is to show both types of maps so that the user may see both the technical results and the conclusions.

Either of the two methods described above can be legitimately used, with the warning that the maps showing conclusions must be originally based on sound data and on the proper method of relating the data elements. The term "propagandistic" used above is not meant in a pejorative sense but is used to highlight the fact that opinion is added to facts before they are presented (and opinions are always one-sided).

Geographic information systems can be used in both ways, and it is imperative to understand which method is being used in any particular case. The results of analysis of several spatially distributed data elements is valid only insofar as the model and the logic relating them are valid and complete. It is necessary to take into account not only the mathematical and statistical relationships among the elements, but their spatial relationships as well. Co-occurrence of critical data elements in the spatial domain must be of significance or there is no good reason to display them on a map or geographic information system format.

\section{THE PROBLEM OF HOLISM AND REDUCTIONISM}

Geographic information systems tend toward the ultimate in reductionism (generally parametric), while integrated mapping systems (Robinove, 1979) tend toward holism. This is a fundamental conflict both on a philosophical basis and on the basis of identifying and solving real problems. Reductionism considers the universe to be composed of separate parts or entities which, in various combinations, make up the whole. Holism considers the universe to be a whole rather than simply the sum of its parts. It is a natural human tendency to separate a whole into its parts, to categorize and classify, to draw boundaries between parts, and to define classes on the basis of rigidly defined boundaries. Boundaries so defined may be useful for some purposes, but they may badly confuse the accomplishment of other purposes. Hofstadter (1979, p. 251) states, "As soon as you perceive an object, you draw a line between it and the rest of the world; you divide the world, artificially, into parts***."

Much of science depends on such division and classification to make sense of the universe. The Earth is divided into the lithosphere, the atmosphere, the hydrosphere, and the overlapping biosphere. The lithosphere is divided, in turn, into various types of rocks on the basis of genetic or mineralogical criteria, and the minerals are themselves divided on the basis of physical or chemical properties. A "landscape" (using the term in the broadest sense) is composed of elements of the lithosphere, atmosphere, hydrosphere, and biosphere. Problems of the use of the landscape by man involve classification of the landscape in such a manner that the classification 


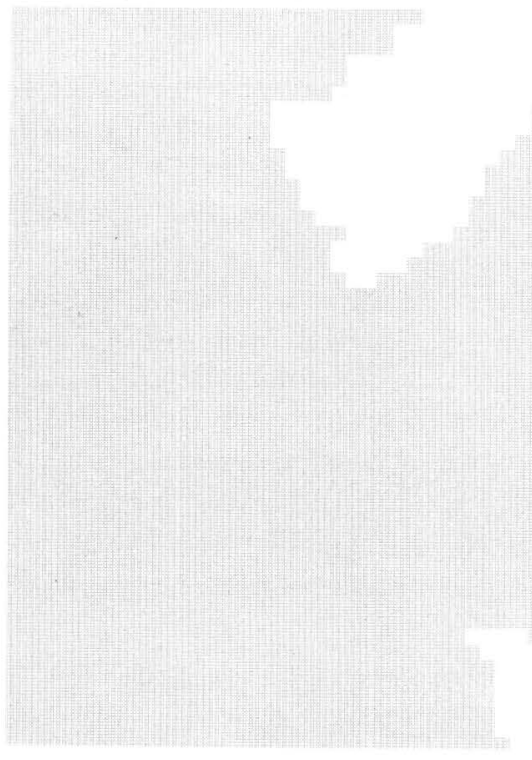

A

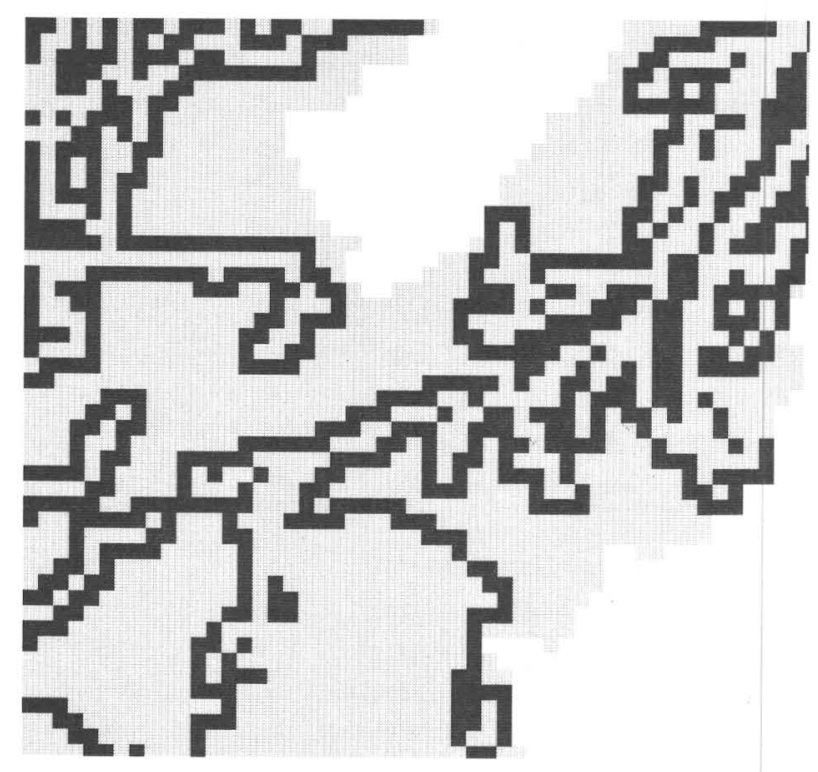

C

Figure 10.-Sets and intersections of sets of water and wastedisposal sites in a river basin. In each illustration, the area of the river basin is grey, the area outside the river basin is white, and the set or intersection of interest is black. Relations are shown graphically in the Venn diagram in figure 9. Sets: (A) River basin, B. (B) Water bodies in the river
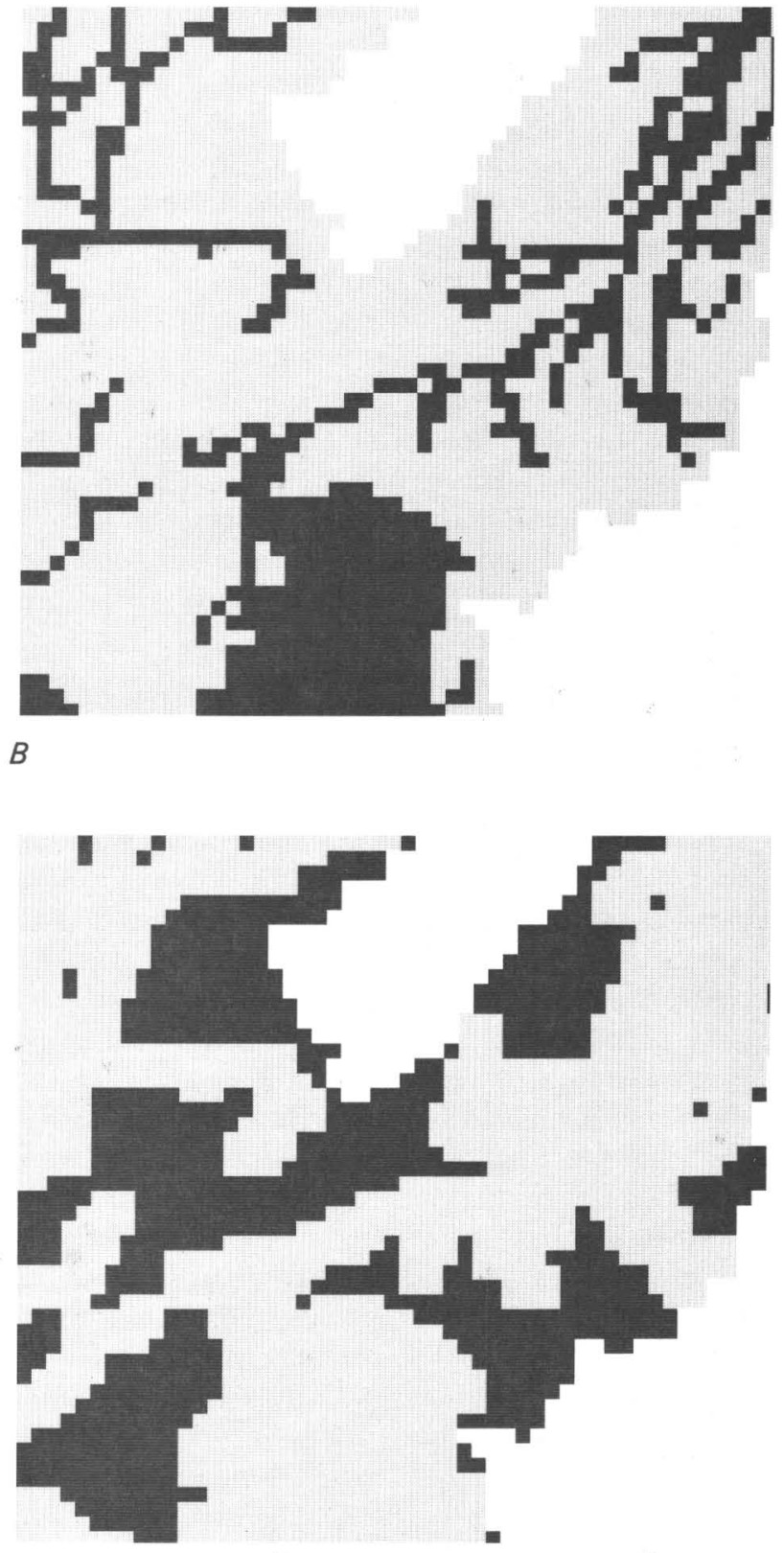

D

basin, $\mathrm{W} \times \mathrm{B}$. (C) Grid cells immediately adjacent to water bodies in the river basin, $\mathrm{W} \times \mathrm{B}$. $(D)$ Grid cells far from water bodies in the river basin, $\sim(\hat{\mathrm{W}}+\mathrm{W}) \times \mathrm{B}$. The sum of $B, C$, and $D$ is $A$, the total area of the river basin, $(\mathrm{W} \times \mathrm{B})+(\mathrm{W} \times \mathrm{B})+$ $\sim(\mathrm{W} \times \mathrm{W}) \mathrm{B}=\mathrm{B}$. 


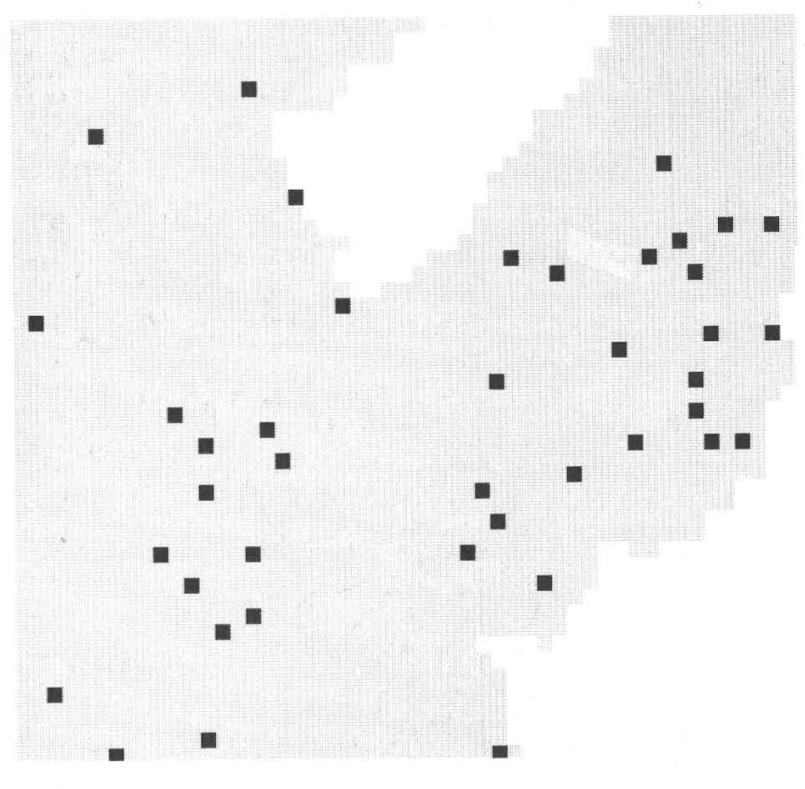

E
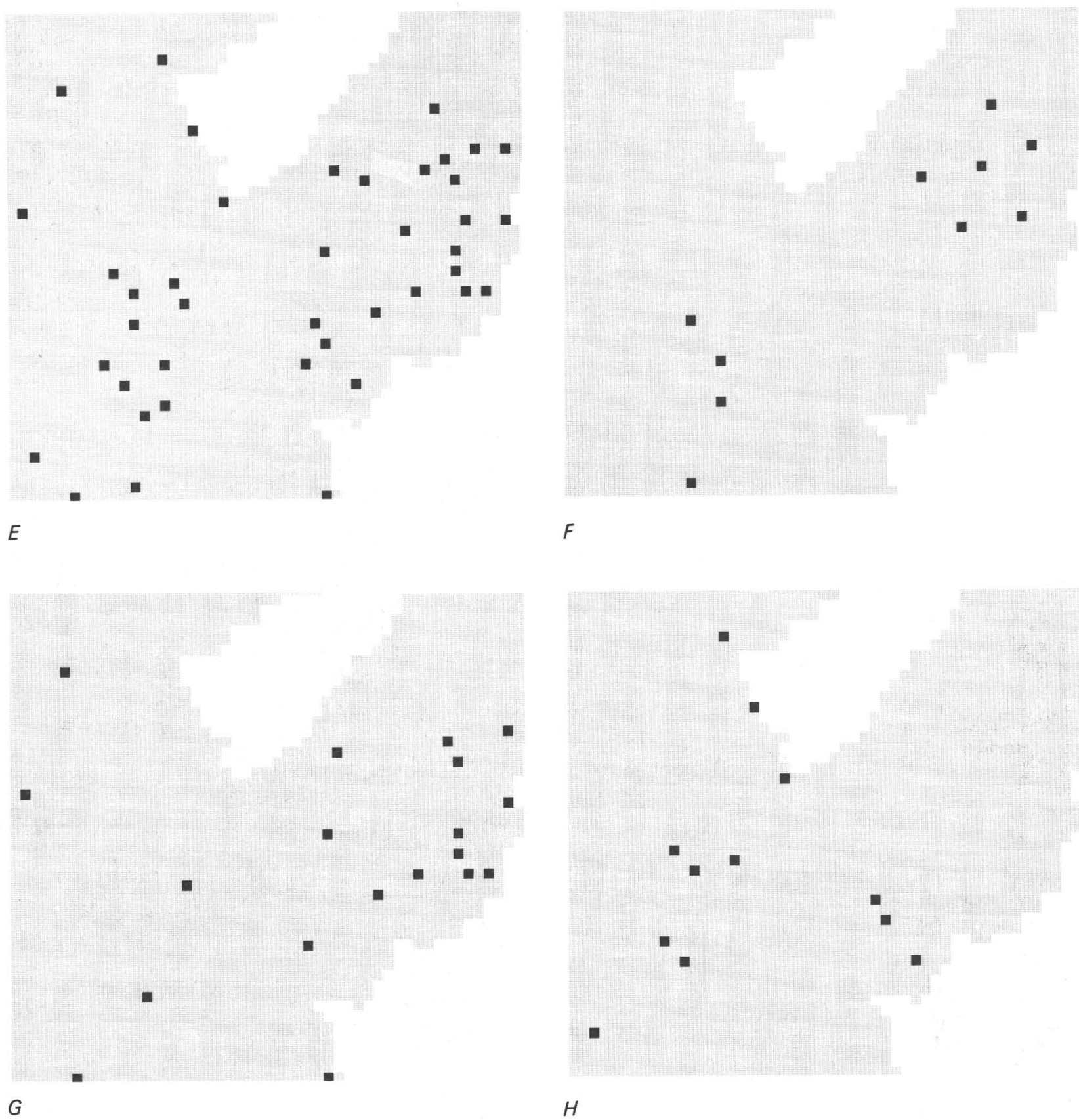

Figure 10.-Continued. $(E)$ All waste disposal sites in the river basin, $\mathrm{D} \times \mathrm{B}$. Intersections of sets: $(F)$ Waste disposal sites within grid cells containing water bodies, $(\mathrm{D} \times \mathrm{B}) \times(\mathrm{W} \times \mathrm{B})$ (intersection of $B$ and $E)$. $(G)$ Waste disposal

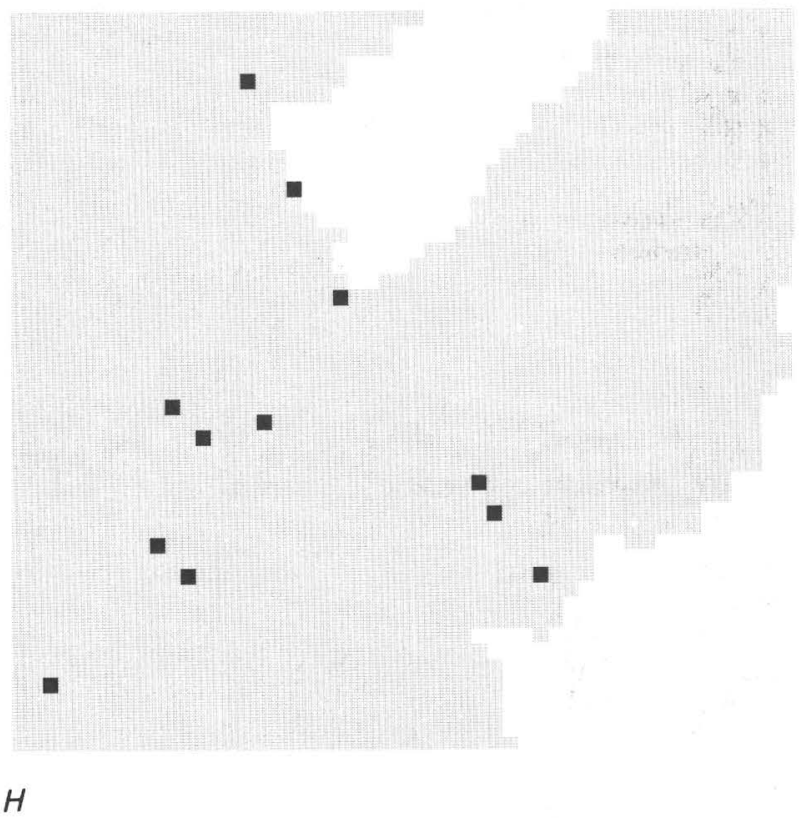

sites in grid cells immediately adjacent to water bodies, $(\mathrm{D} \times \mathrm{B}) \times(\mathrm{W} \times \mathrm{B})$ (intersection of $C$ and $E)$. (H) Waste disposal sites in grid cells far from water bodies, $(\mathrm{D} \times \mathrm{B}) \times$ $\sim(\widehat{\mathrm{W}}+\mathrm{W}) \times \mathrm{B}$ (intersection of $D$ and $E)$. 


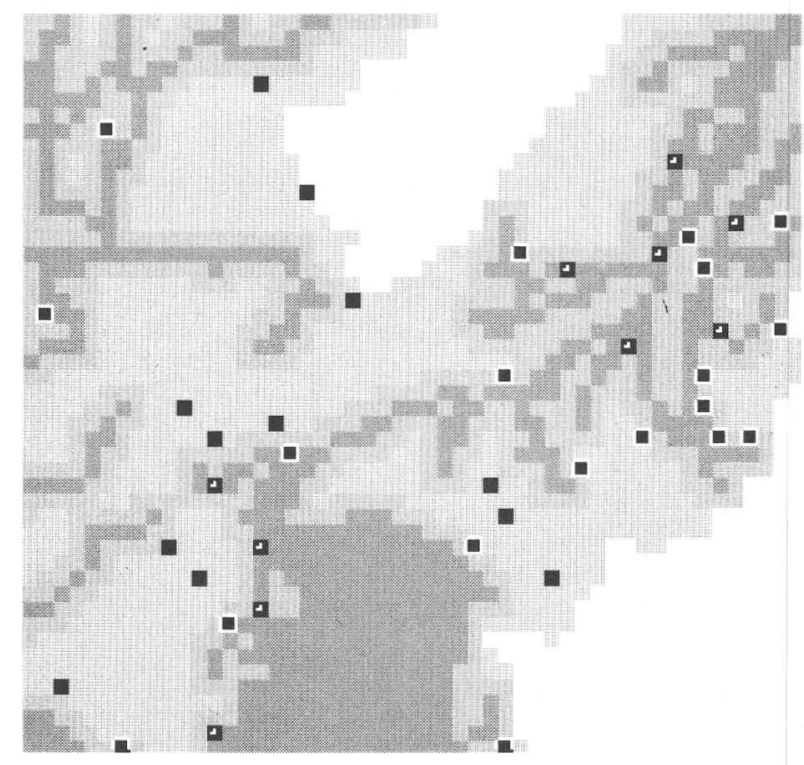

FIGURE 11.-Combination of individual sets and intersections of sets. White-areas outside the drainage basin, B. Gray shades-areas within the drainage basin, B: Dark Graygrid cells containing water, $\mathrm{W} \times \mathrm{B}$; Medium Gray-grid cells adjacent to water, $\hat{W} \times B$; Light Gray-grid cells far from water, $\sim(\hat{W}+W) \times B$. Black cell with white symbol-waste disposal site in grid cell with water, $\mathrm{D} \times \mathrm{W} \times \mathrm{B}$. Black cell with white border-waste disposal site in grid cell adjacent to water, $\mathrm{D} \times \hat{\mathrm{W}} \times \mathrm{B}$. Black cell-waste disposal site far from water, $\mathrm{D} \times \sim(\mathrm{W}+\mathrm{W}) \times \mathrm{B}$ above $\mathrm{w}$.

is applicable to the problem. Such a problem might be the conversion of a natural grassland to irrigated farming with the attendant buildup of an economic infrastructure. Considered in a reductionistic manner, the solution to the problem must involve the individual facets such as the grass, the soil, the water resources, the engineering properties of the site, transportation, and so forth. This is a prime use of geographic information systems, in which all of the known parametric attributes of the site are defined, measured, and mapped and the geographic information system relates them to the problem and the solution. Considered in a holistic manner, the relations among the attributes of the site become the primary focus and, in addition, the relation of the site to the surrounding area is considered.

The operation of a geographic information system depends on two factors, (1) the availability in the proper form and format of all of the data that are needed and (2) the availability of the relational or process model that operates on the data to produce a solution to a problem. At the present state of the art, it is possible to collect and place in the proper form the data that are required in a reductionistic manner, which means that the information that is considered to be of significance to the problem is classified into categories that are relevant. The data are manipulated by mathematical, statistical, or Boolean logical operations to produce problem solutions. At the present time the solutions are basically reductionistic.

Holistic solutions are possible only if the original data are collected and represented in a holistic fashion and the algorithms that operate on the data represent a holistic view of the problem and its solution. An example may serve to clarify the difference between the two views. In an area where animal grazing is the principal use of the land, it is necessary to manage the land to maximize the production of animal products without degrading the carrying capacity of the land below a certain sustainable level. A reductionist method of mapping the carrying capacity of the land involves classifying each of the factors of geomorphic features, soils, and vegetation and modeling these to determine the carrying capacity. A holistic method involves integrated mapping of the complex of geomorphic features, soils, and vegetation, and from this deriving the carrying capacity of the individual complexes. A major tenet of the holistic integrated mapping approach is that each parcel of land is considered unique. This is in contrast to the reductionistic view, which sets up classification schemes and then maps each parcel of land in such a way that it must fit into a niche in a selected classification. In essence, the reductionistic view makes it difficult to map and describe ecotones, or areas of transitions between classes, while the holistic view considers transitions to be more common than pure classes and affords them an easily recognizable and mappable status.

Geographic information system algorithms at present are based almost completely on Boolean logical operations. They are capable of theoretically simple operations that characterize parcels of land in terms of the relations of their reductionistic attributes. More sophisticated models can, of course, be applied to the original data to derive secondary or tertiary attributes, and these later attributes can in turn be manipulated by geographic information systems algorithms. Nevertheless, the ability to model processes with the reductionistic methods of geographic information systems is in its infancy, and the links between modeling in various fields and the geographic information systems are far from being well de- 
fined. It should be a goal of research in these fields to achieve a holistic view that will allow the modeling and relational techniques to cope with the complexities of nature and man's influence on it in a complete problem-solving manner.

\section{CONCLUSIONS}

Digital geographic information systems operate on logical principles. Those principles should be understood by the people who enter data into systems, by the programmers who design the operations, and by the users who expect answers to problems from the systems. Users must be capable of phrasing their questions in forms that are amenable to the data and the operations.

Many of the rather complicated operations that are performed on data planes in a geographic information system can be reduced to logical primitive operations (illustrated by Venn diagrams and expressed in symbolic notation) that are more readily understood by users than the algorithms and programs that are actually used in the systems. It is hoped that this understanding of those logical operations will aid users in making the most effective use of digital geographic information systems.

\section{SELECTED REFERENCES}

Calkins, H.W., and Tomlinson, R.F., 1977, Geographic information systems, methods and equipment for land use planning 1977: Ottawa, Canada, International Geographical Union, 394 p.
Carnap, Rudolph, 1958, Introduction to symbolic logic and its applications, New York, Dover Press.

Eco, Umberto, 1984, The name of the rose: New York. Warner Books, 640 p.

Hofstadter, Douglas, 1979, Godel, Escher, Bach-An eternal golden braid: New York, Basic Books, 777 p.

Jupp, D.L.B., and Mayo, K.K., 1982, The use of residual images in Landsat image analysis. Photogrammetric Engineering and Remote Sensing, v. 48, no. 4, p. 595-604.

Luckey, R.R., and Ferrigno, C.F., 1982, A data-management system for areal interpretive data for the High Plains in parts of Colorado, Kansas, Nebraska, New Mexico, Oklahoma, South Dakota, Texas, and Wyoming. U.S. Geological Survey Water-Resources Investigations 82-4072, $112 \mathrm{p}$.

Mandelbrot, Benoit, 1977, Fractals: Form, chance, and dimension, New York, W.H. Freeman Co., 297 p.

McHarg, I.L., 1969, Design with nature: New York, Natural History Press, 198 p.

Negoita, C.V., 1981, Fuzzy systems. London, Abacus Press, $111 \mathrm{p}$.

Nystuen, J.D., 1968, Identification of some fundamental practical concepts, in Berry, J.L.B., and Marble, D.F., Spatial analysis-Reader in statistical geography. Englewood Cliffs, N.J., Prentice-Hall, p. 35-41.

Robinove, C.J., 1979, Integrated terrain mapping with digital Landsat images in Queensland, Australia. U.S Geological Survey Professional Paper 1102, 39 p.

1981, The logic of multispectral classification and mapping of land. Remote Sensing of Environment, v. 11, p. 231-244.

Varnes, D.J., 1974, The logic of geological maps with reference to their interpretation and use for engineering purposes. U.S. Geological Survey Professional Paper 837, 48 p.

Werkmeister, W.H., 1949, An introduction to critical thinking: Lincoln, Nebr., Johnson Publishing Co., $66^{`} \mathrm{p}$.

Zadeh, L.A., 1965, Fuzzy sets and systems. Symposium on System Theory, Polytechnic Institute of Brookl:n, 1964, Proceedings, p. 29-39. 


